\title{
The Interaction of Impurity Oxygen with Radiation Defects in Silicon Crystal
}

Hrant N. Yeritsyan1*, Aram A. Sahakyan1, Norair E. Grigoryan1, Eleonora A. Hakhverdyan1, Vachagan V. Harutyunyan1, Agasi S. Hovhannisyan1, Vahan A. Sahakyan², Armenuhi A. Khachatryan², Bagrat A. Grigoryan'3, Laura S. Hakobyan³, Gayane A. Amatuni ${ }^{3}$, Ashot S. Vardanyan ${ }^{3}$, Vasili M. Tsakanov ${ }^{3}$

${ }^{1}$ A.I. Alikhanyan National Science Laboratory (Yerevan Physics Institute), Yerevan, Armenia

${ }^{2}$ National Institute of Metrology, Yerevan, Armenia

${ }^{3}$ CANDLE Synchrotron Research Institute, Yerevan, Armenia

Email: "grant@yerphi.am

Received 8 July 2015; accepted 17 November 2015; published 20 November 2015

Copyright (C) 2015 by authors and Scientific Research Publishing Inc.

This work is licensed under the Creative Commons Attribution International License (CC BY). http://creativecommons.org/licenses/by/4.0/

(c) †) Open Access

\section{Abstract}

Present paper describes the investigation of vacancy (V) and interstitial (I) annihilation on oxygen atoms by means of infrared (IR) absorption and Hall-effect measurements of the accumulation of vacancy-oxygen complexes (VO) in Si crystals at high energy electron irradiation. Silicon samples, containing along with isolated oxygen atoms, more complicated oxygen quasi-molecules of $\mathrm{SiO}_{\mathrm{n}}(\mathrm{n}$ $=1,2,3 \ldots)$ type, were used. At isochronal and isothermal annealing in the temperature range of $300^{\circ} \mathrm{C}-350^{\circ} \mathrm{C}$, apart from the reaction of vacancy capturing by oxygen atoms with formation of A-centers, more complicated reactions with participation of vacancies and oxygen atoms were observed: A-centers, oxygen containing quasi-molecules. A model is suggested to describe the observed processes that are qualitatively different from those taking place in samples containing completely dissociated oxygen.

\section{Keywords}

Impurity Oxygen, Silicon Crystal, Electron Irradiation, Infrared (IR) Absorption Spectra, Annealing, Vacancy, Interstitial Atom

\section{Introduction}

Oxygen atoms play an important role in radiation defect formation both for point defects and clusters in silicon

${ }^{*}$ Corresponding author. 
crystal. They may be in different states in silicon which are electrically active (thermodonors $\mathrm{SiO}_{4}$, thermoacceptors $\mathrm{SiO}_{2}$ and $\mathrm{SiO}_{3}$ ) [1]-[3]; some are optically active [4]-[6], and others are paramagnetic (e.g. A-centers which have captured an electron) [7], [8]. Therefore, the reconstruction of impurity oxygen configurations in silicon essentially affects the sample properties. In the present work such a reconstruction was achieved after irradiation of silicon samples by fast electrons at room temperature, producing vacancies $\mathrm{V}$ and "odd" silicon atom of $\mathrm{Si}_{\mathrm{i}}$ which were mobile under the irradiation conditions and subsequent heating. The oxygen impurity concentration in the samples treated, highly exceeded those of other impurities that could capture vacancies (V), and the irradiation led to a substantial reconstruction of oxygen containing defects.

A similar investigation has been reported in [5], [8]-[10], which show the disappearance of A-centers following silicon irradiation and annealing at $300^{\circ} \mathrm{C}$ leading to the appearance of an infrared absorption band with a maximum $887 \mathrm{~cm}^{-1}$. This fact is naturally attributed to the $\mathrm{A}+\mathrm{O}_{\mathrm{I}} \rightarrow \mathrm{VO}_{2}$ reaction which takes owing to A-centre diffusion. Heating the samples to higher temperatures resulted in a further reconstruction of IR bands, which is explained by the appearance of centers with three and more $\mathrm{O}_{\mathrm{I}}$ atoms. This relatively simple picture is possible in silicon where the concentration of isolated oxygen atoms is much higher than the oxygen concentration in other oxygen containing centers. However, a lot of silicon samples exhibit a considerable concentration of more complicated oxygen containing centers in the form of isolated $\mathrm{SiO}_{\mathrm{n}}$ and other impurities (carbon, boron), microcrystalline precipitates of different dimensions. Such centers contribute to the absorption band of local vibrations of the Si-O bond near $9 \mu \mathrm{m}$ (which is usually poorly expressed at room temperatures).

The present work was conducted on irradiated silicon specimens which included isolated oxygen atoms (at the concentration higher than $5 \times 10^{17} \mathrm{~cm}^{-3}$ ) as well as more complicated oxygen-containing centers, $\mathrm{O}^{*}$. Annealing of irradiated samples was carried out to elucidate the thermal hardness of radiation defects.

\section{Experiment and Measurement Results}

Specimens of n-and p-type silicon, containing oxygen at the $(0.5-1.3) \times 10^{18}$ concentration and carbon at the (0.3 - 0.8) $\times 10^{18} \mathrm{~cm}^{-3}$ (Chohralski grown $\mathrm{Si}$ ) concentration, were irradiated on the liner accelerator of Yerevan Physics Institute by electrons with energy $50 \mathrm{MeV}$ and at AREAL (Advanced Research Electron Accelerator Laboratory) of CANDLE organization with electron energy of 3.5 MeV. Note that the mentioned oxygen concentration equals to the upper limit for oxygen atoms solubility in Si at Si melting temperature, and it decreases with temperature decrease. Hence, at common conditions the oxygen solid solution is in saturated state and oxygen atoms may be activated under external influences, for example, irradiation [1]-[3].

The infrared absorption spectra of the irradiated samples showed a number of absorption bands with maxima at 1.8; 3.3; 3.45; $3.6 \mu \mathrm{m}, 12 \mu \mathrm{m}$ and $11.6 \mu \mathrm{m}$ wavelengths. Their intensity increases as the dose grows. The intensity of the $9 \mu \mathrm{m}$ (oxygen) and $16 \mu \mathrm{m}$ (carbon) bands observed before irradiation, decreased with the dose increase. Following irradiation, isochronal and isothermal annealing was carried out successively at temperature ranging from $80^{\circ} \mathrm{C}$ to $350^{\circ} \mathrm{C}$. Annealing at $270^{\circ} \mathrm{C}$ for 8 hours led to the complete disappearance of absorption due to divacancies; the absorption intensity at the $829 \mathrm{~cm}^{-1}$ region somewhat increased. This is obviously due to reactions between impurity oxygen and vacancies released at annealing of divacancies. Thus, the subsequent study of annealing in the interval from $300^{\circ} \mathrm{C}$ to $350^{\circ} \mathrm{C}$ was carried out with silicon samples where defects containing vacancies coupled with oxygen atoms were dominant.

Figure 1 and Figure 2 show the absorption spectra at room temperature in the $1106 \mathrm{~cm}^{-1}$ region before irradiation and its variation at different irradiation doses, and during annealing, respectively. An approximation of the measured absorption curve in the form of Gaussian is used to determine the spectrum structure. The band parameters, including the maximum positions and the number of bands, were varied and were defined from the mean-square minimum condition using computer simulation [9]. The points in Figure 2 show the elementary bands obtained after expansion of the experimental curve 1.

The change of intensity variation of the elementary absorption bands during irradiation (Figure 3) and isothermal annealing (Figure 4) show that the absorption bands at 1045, 1098, and $1106 \mathrm{~cm}^{-1}$ are sensitive to both irradiation and annealing. The relation between the intensities of these bands changes with irradiation and annealing; therefore, the bands must be referred to different centers. The intensities of 1098 and $1106 \mathrm{~cm}^{-1}$ bands decrease with irradiation, the $1098 \mathrm{~cm}^{-1}$ band decreases more sharply than the band at $1106 \mathrm{~cm}^{-1}$. The intensity of $1098 \mathrm{~cm}^{-1}$ band grows with annealing while the intensity of band $1106 \mathrm{~cm}^{-1}$ decreases (before they reach saturation following prolonged isothermal annealing). The band $1150 \mathrm{~cm}^{-1}$ doesn't vary either during irradiation or annealing, i.e. it is not related to the centers participating in the reactions. 


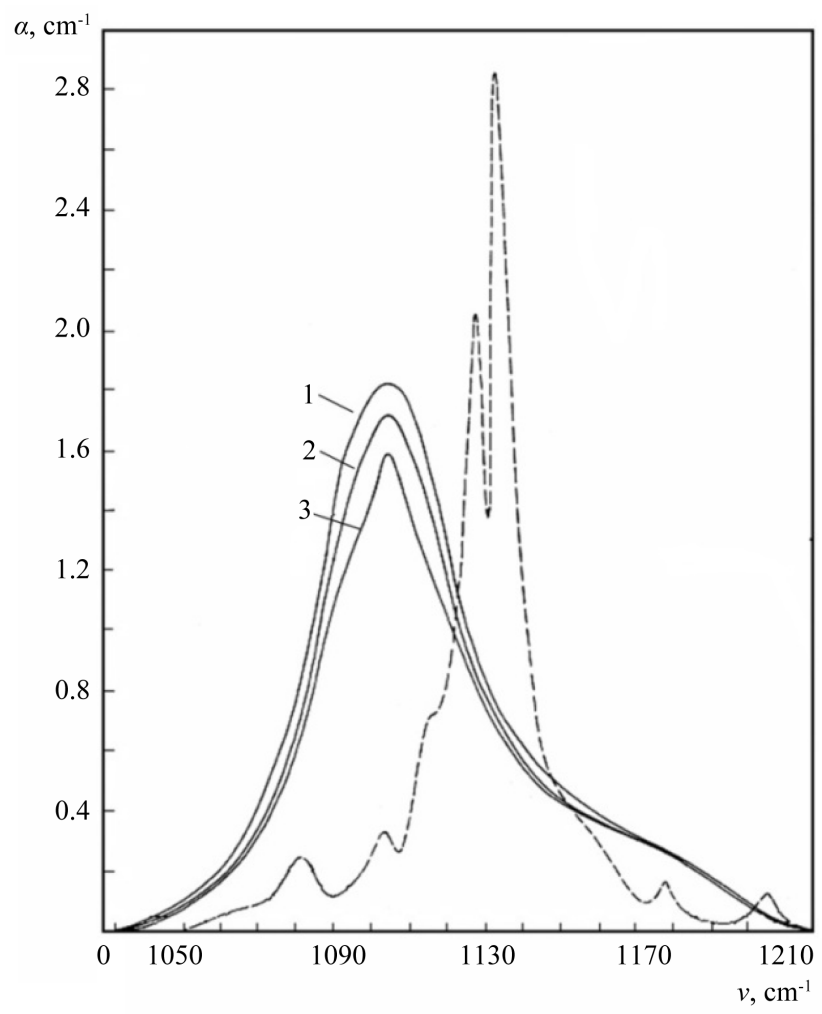

Figure 1. Change of the shape of the $9 \mu \mathrm{m}$ spectral absorption band in p-type silicon specimens with oxygen concentration of $6 \times 10^{17} \mathrm{~cm}^{-3}$ as a result of irradiation by 50 $\mathrm{MeV}$ electrons, measured at room temperature. (1): before irradiation; after irradiation by doses; (2): $1.3 \times 10^{17} \mathrm{el} / \mathrm{cm}^{2}$; (3): $1.1 \times 10^{18} \mathrm{el} / \mathrm{cm}^{2}$; dotted curve: $9 \mu \mathrm{m}$ absorption band obtained at liquid helium temperature after irradiation by dose of $1.1 \times 10^{18}$ $\mathrm{el} / \mathrm{cm}^{2}$.

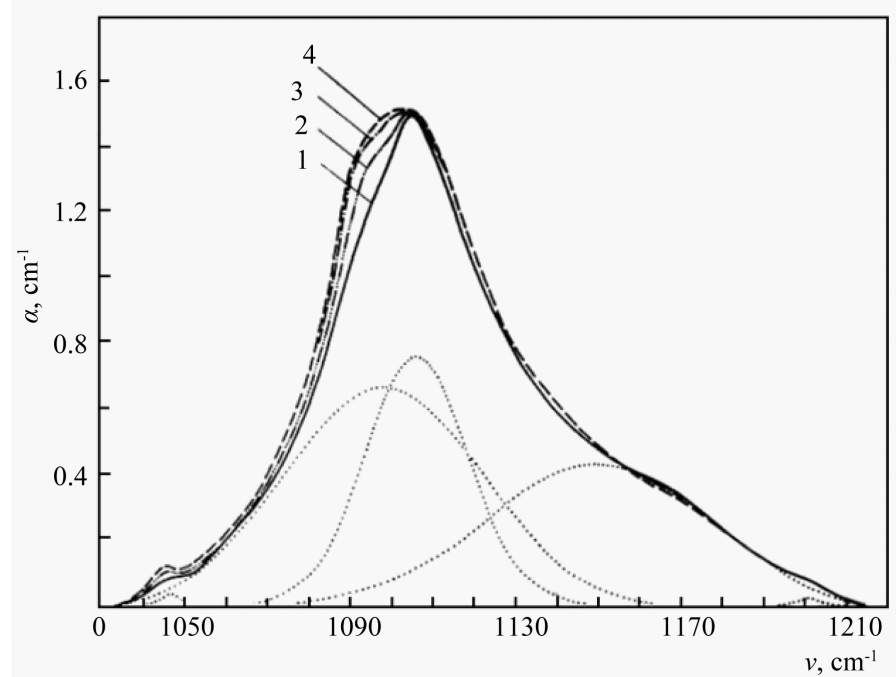

Figure 2. $9 \mu \mathrm{m}$ spectral absorption band in p-Si specimens with oxygen concentration of $6 \times 10^{17} \mathrm{~cm}^{-3}$ as a result of irradiation by $50 \mathrm{MeV}$ electrons measured at room temperature during isothermal annealing at $\mathrm{T}=310^{\circ} \mathrm{C}$. (1): Initial point (the specimen irradiated with $1.1 \times 10^{18} \mathrm{el} / \mathrm{cm}^{2}$ and annealed (2): 30 min later; (3): 80 min later; (4): $380 \mathrm{~min}$ later. The dotted line shows the elementary bands obtained after computer decomposition of the main band (1). 


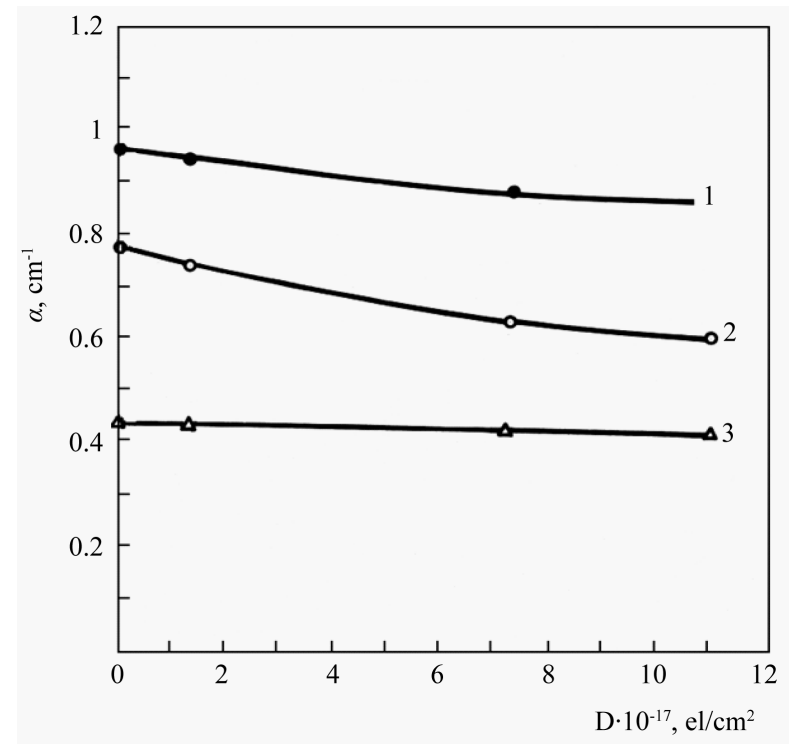

Figure 3. Irradiation dose dependence of absorption coefficients of the decomposed elementary bands with maxima at frequencies: (1): $v=1106 \mathrm{~cm}^{-1}$; (2): $v=1098 \mathrm{~cm}^{-1}$; (3): $v=$ $1150 \mathrm{~cm}^{-1}$.

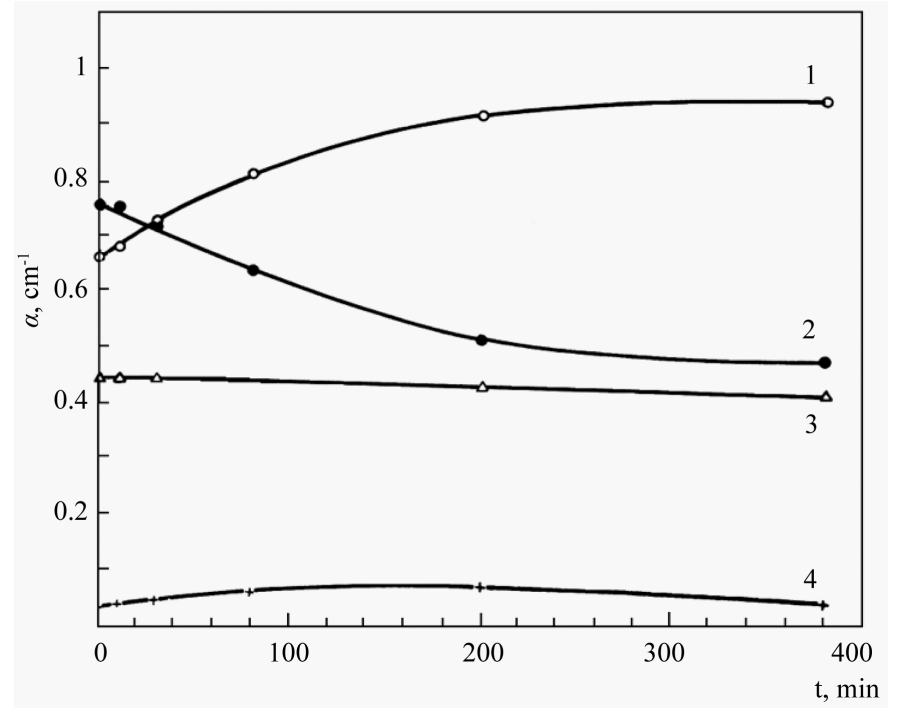

Figure 4. Change at $320^{\circ} \mathrm{C}$ isothermal annealing of the decomposed elementary bands with maxima at frequencies: (1): $1098 \mathrm{~cm}^{-1}$; (2): $1106 \mathrm{~cm}^{-1}$; (3): $1150 \mathrm{~cm}^{-1}$; (4): $1045 \mathrm{~cm}^{-1}$.

The $1045 \mathrm{~cm}^{-1}$ band which has been identified as $\mathrm{SiO}_{4}$ complex was not observed in samples either in the original condition or after irradiation at room temperature. It first appeared during annealing of the irradiated specimens at $100^{\circ} \mathrm{C}$. Figure 5 shows the dose dependences of the absorption coefficient of the 829 and $862 \mathrm{~cm}^{-1}$ bands. The first band is indentified with $\mathrm{O}_{\mathrm{I}} \mathrm{V}$, i.e., with A-centers, and the second one, which we shall call $\mathrm{X}$-band, is due to more complicated centers containing vacancies. The ratio of absorption intensities between $\mathrm{X}$-band and A-band differs from specimen to specimen (in [5] the generation of A-centers with irradiation was not followed by X-centers at all); hence, the $862 \mathrm{~cm}^{-1}$ band appears when vacancies are captured by centers other than $\mathrm{O}_{\mathrm{I}}$. The annealing leads to a decrease and vanish of the 852 and $829 \mathrm{~cm}^{-1}$ bands at $310^{\circ} \mathrm{C}$. In type I specimens (with oxygen concentration of $1.3 \times 10^{18} \mathrm{~cm}^{-3}$ ) this is accompanied by the appearance of the $887 \mathrm{~cm}^{-1}$ absorption band $\left(\mathrm{VO}_{2}\right.$ centre). In type II specimens (with oxygen concentration up to $6 \times 10^{17} \mathrm{~cm}^{-3}$ ) the annealing of 862 and $829 \mathrm{~cm}^{-1}$ bands results in only weak traces of an absorption increase at $887 \mathrm{~cm}^{-1}$. The main 


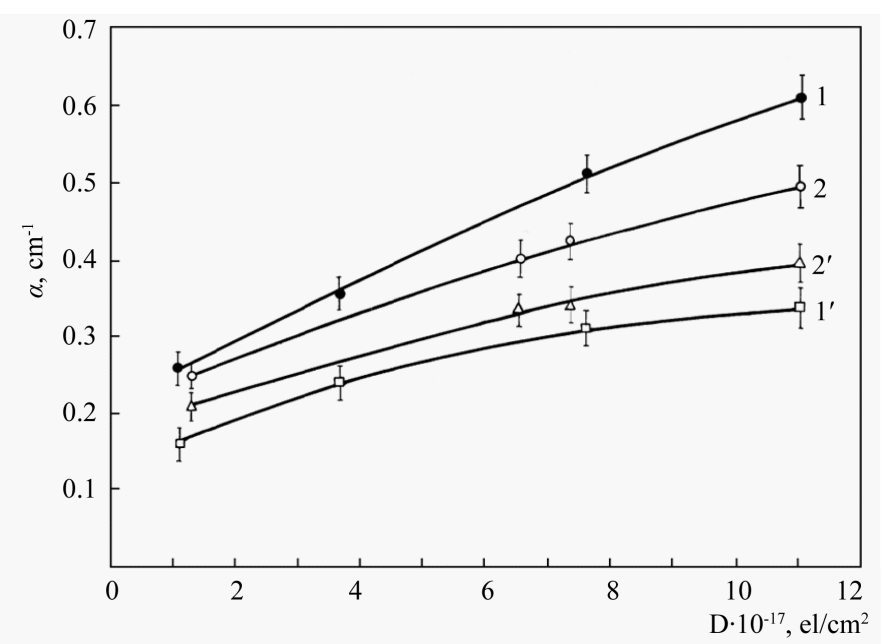

Figure 5. Irradiation dose dependence of absorption coefficients of bands: (1), (2): $829 \mathrm{~cm}^{-1}$, and (1'), (2'): $862 \mathrm{~cm}^{-1}$. For samples: (1), (1'): Si-p-20 $(\rho \approx 20 \Omega \cdot \mathrm{cm}$, with concentrations of oxygen $\approx 1.3 \times 10^{18} \mathrm{~cm}^{-3}$, carbon $\left.\approx 1.7 \times 10^{17} \mathrm{~cm}^{-3}\right)$; and $(2)$, $\left(2^{\prime}\right)$ : Si-p-250 $\left(\rho \approx 250 \Omega \cdot \mathrm{cm}\right.$, with concentrations of oxygen $\approx 6 \times 10^{17} \mathrm{~cm}^{-3}$, carbon $\approx 5.5$ $\left.\times 10^{17} \mathrm{~cm}^{-3}\right)$.

processes in annealing are those of intensity decrease at $1106 \mathrm{~cm}^{-1}\left(\mathrm{O}_{\mathrm{I}}\right)$ band and an intensity increase at 1098 $\mathrm{cm}^{-1}$ band.

It is seen from Figure 6 that the temperature dependencies of main charge carrier concentration for n-Si with specific resistances $100 \Omega \cdot \mathrm{cm}$ and $700 \Omega \cdot \mathrm{cm}$ have nearly the same energetic level in the forbidden gap of Si owing to oxygen containing centers (A-centers) or other precipitates with $\mathrm{O}^{*}$ which indicated by the existence of an additional slop on the curve of Figure 7. Besides, these centers displayed at higher temperatures in samples with higher specific resistance $(700 \Omega \cdot \mathrm{cm})$ where the main charge carrier concentration is lower and not difficult observe other energetic levels (connected with oxygen atoms in irradiated Si and probably their clusters) in the forbidden gap of silicon zone structure.

Note, that main charge carrier concentration temperature dependences are given vs 1000/T which is convenient in order to define other important semiconductor parameters too. For instance, from the slope of n(1000/T) curve it is possible to calculate the activation energy of radiation defects, i.e., their energetic position in the forbidden gap of semiconductor zone structure which allows elucidate the physical nature of radiation defect: simple point (vacancy, interstitial atom), complex (point + impurity atom), clusters, disordered regions in materials. From Figure 6 one can calculate the activation energy $\Delta \mathrm{E}=0.18 \mathrm{eV}$ which is known as so called "A-center" (vacancy + oxygen atom in silicon). Besides, it is seen from Figure 6, Figure 7 and Table 1 that there is a significant decrease in carrier concentration (at room temperatures) after irradiation, which points to the availability of more deep energetic levels of other radiation defects with higher concentration (about $2.6 \times 10^{13} \mathrm{~cm}^{-3}$ ).

\section{Discussion}

According to Section 2, in non-irradiated silicon specimens one should consider two types of centers which capture vacancies after irradiation, viz. isolated $\mathrm{O}_{\mathrm{I}}$ atoms $\left(1106 \mathrm{~cm}^{-1}\right)$ and $\mathrm{O}^{*}$ centers $\left(1098 \mathrm{~cm}^{-1}\right)$. The latter are apparently some microscopic oxygen atom conglomerations, such that the oscillation frequency of the Si-O bond in the conglomerate near the value of $1098 \mathrm{~cm}^{-1}$ depends only slightly on number of oxygen atoms in the conglomerate. The capture of a vacancy by a conglomerate or the presence of an impurity atom in it may substantially distort the oscillation frequency of the corresponding bond but it slightly affects the frequencies of the other conglomerate bonds. Therefore, Si-O bonds oxygen conglomerates, which differ somewhat by the number of oxygen atoms or by the presence of other impurity atoms, may be responsible for the absorption at $1098 \mathrm{~cm}^{-1}$.

As we see from Section 2, the $\mathrm{O}^{*}$ centers have somewhat larger summary $\mathrm{V}$ capture cross-section than $\mathrm{O}_{\mathrm{I}^{-}}$ centers. When $\mathrm{V}$ is captured by an $\mathrm{O}_{\mathrm{I}}$ atom the absorption at $1106 \mathrm{~cm}^{-1}$ decreases and an A-centre appears, which gives rise to absorption at $829 \mathrm{~cm}^{-1}$. When $\mathrm{V}$ is captured by an $\mathrm{O}^{*}$ centre, the absorption at $1098 \mathrm{~cm}^{-1}$ 


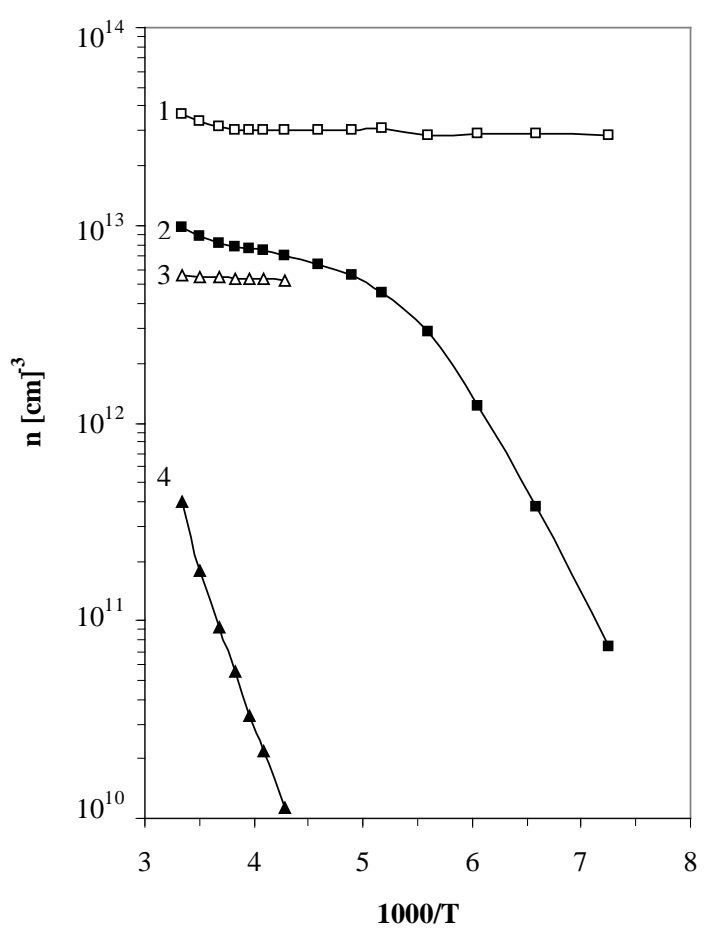

Figure 6. Temperature dependences of main charge carrier concentration for $\mathrm{n}-\mathrm{Si}$ with specific resistances: $100 \Omega \cdot \mathrm{cm}$ before (1) and after irradiation by electrons with energy 3.5 MeV (2) and $700 \Omega \cdot \mathrm{cm}$ before (3) and after (4) irradiation by electrons with energy $3.5 \mathrm{MeV}$. The latter curve slope indicates to cluster of oxygen containing centers.

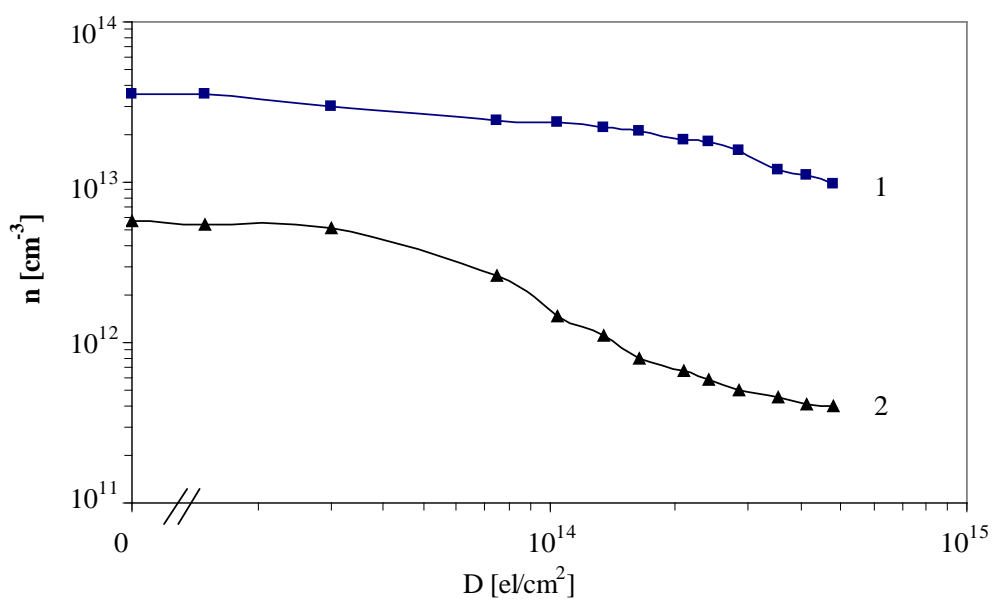

Figure 7. Irradiation dose dependence of main charge carrier concentration for $\mathrm{n}-\mathrm{Si}$ with specific resistances of $100 \Omega \cdot \mathrm{cm}(1)$ and $700 \Omega \cdot \mathrm{cm}(2)$ after irradiation by electrons with energy $3.5 \mathrm{MeV}$ at $\mathrm{T}=300^{\circ} \mathrm{C}$.

decreases owing to the distortion of a Si-O bond in the $\mathrm{O}^{*}$ centre and the absorption of the distorted bond occurs at $862 \mathrm{~cm}^{-1}$ (X-band). The other Si-O bonds in the $\mathrm{O} * \mathrm{~V}$ centre doesn't change. However, we were led by the experimental evidence to dwell on the mechanism of A-centre annealing, which is manifested as activation of the motion of an A-centre as whole at $300^{\circ} \mathrm{C}$, and its subsequent capture by other centers. According to our scheme, at $300^{\circ} \mathrm{C}$ when A-centre motion is activated, A-centre detachment from the $\mathrm{O}^{*}$ centre can be expected. But from the results of Section 2 follows that the binding force of an oxygen atom in the conglomerate is sufficiently high so that an isolated vacancy rather than an A-centre is detached from the $\mathrm{O} * \mathrm{~V}$ centre. 
Table 1. Electrical parameters of silicon crystal at temperature $\mathrm{T}=300 \mathrm{~K}$ before $(\mathrm{D}=0)$ and after irradiation by electron beam with energy $3.5 \mathrm{MeV}$ and dose $\mathrm{D}=4.8 \times 10^{14}$ (AREAL linear accelerator).

\begin{tabular}{ccccc}
\hline Sample & \multicolumn{2}{c}{$\mathrm{n}-\mathrm{Si} ; 100(\Omega \cdot \mathrm{cm})$} & $\mathrm{n}-\mathrm{Si} ; 700(\Omega \cdot \mathrm{cm})$ \\
\hline Irradiation Dose $\left[\mathrm{el} / \mathrm{cm}^{2}\right]$ & 0 & $4.8 \times 10^{14}$ & 0 & $4.8 \times 10^{14}$ \\
Carrier concentration $\mathrm{n}\left[\mathrm{cm}^{-3}\right]$ & $3.6 \times 10^{13}$ & $9.8 \times 10^{12}$ & $5.6 \times 10^{12}$ & $4.2 \times 10^{12}$ \\
Specific conductivity $\sigma[\Omega \cdot \mathrm{cm}]^{-1}$ & $6.1 \times 10^{-3}$ & $1.5 \times 10^{-3}$ & $1.5 \times 10^{-3}$ & $6.3 \times 10^{-3}$ \\
Carrier mobility $\mu\left[\mathrm{cm}^{2} / \mathrm{V} \cdot \mathrm{s}\right]$ & 1050 & 950 & 1700 & 800 \\
\hline
\end{tabular}

Secondary trapping of the free vacancy by some $\mathrm{O}^{*}$ centre is possible but this position of $\mathrm{V}$ is unstable again, and such a process only prolongs the annealing time. If, on the other hand, the free vacancy is captured by an $\mathrm{O}_{\mathrm{I}}$ atom, an A-centre appears which is identical to those formed directly at irradiation and is mobile at the annealing temperature.

The diffusion of A-centers leads to their capture by $\mathrm{O}_{\mathrm{I}}$ and $\mathrm{O}^{*}$ centers with the decrease in A-centre absorption at $829 \mathrm{~cm}^{-1} . \mathrm{VO}_{2}$ centers $\left(887 \mathrm{~cm}^{-1}\right)$ result from the $\mathrm{A}+\mathrm{O}_{1}$ reaction. With the A-centre capture by $\mathrm{O}$ an $\mathrm{O} * \mathrm{~V}$ centre emerges, which contains, however, an odd oxygen atom. This circumstance, as mentioned before, slightly distorts the $\mathrm{O}^{*}$ centre absorption at $1098 \mathrm{~cm}^{-1}$, but changes the absorption from the A-centre at $829 \mathrm{~cm}^{-1}$ to the $862 \mathrm{~cm}^{-1} \mathrm{X}$-band ( $\mathrm{Si}-\mathrm{O}$ bond in $\mathrm{O}$ centre $+\mathrm{V}$ ). Then $\mathrm{V}$ is again detached from the $\mathrm{OV}$ centre and so on. This type of center which releases vacancies after capturing A-centers is called a vacancy release center.

The above picture explains in qualitative terms the effect of decreased $\mathrm{O}_{\mathrm{I}}$ atoms absorption during annealing even in samples where A-center capture by $\mathrm{O}_{\mathrm{I}}$ atoms is not very effective owing to strong A centers sinks on $\mathrm{O}^{*}$. The vacancies which are released from $\mathrm{O}^{*} \mathrm{~V}$ centers are acting as catalysts to coagulate $\mathrm{O}_{\mathrm{I}}$ atoms into conglomerates. If no vacancy capture centers other than $\mathrm{O}_{1}$ and $\mathrm{O}^{*}$ existed, the annealing should result in the complete disappearance of isolated oxygen atoms and the $1106 \mathrm{~cm}^{-1}$ absorption band. But capture takes place which can be in dislocations, specimen surface, or other impurity centers which were either optically inactive or have lower concentrations. Here a vacancy recombination is possible, i.e., its filling by either a silicon atom or an impurity atom; such a centre can be named vacancy annihilation centre. If the bond of the vacancy with the centre is strong, but does not annihilate, at higher temperatures it can participate in various centers [11]-[15]. These centers can be called vacancy trapping centers at appropriate temperatures. The availability of both vacancy annihilation and vacancy trapping centers leads to a gradual decrease in the free $\mathrm{V}$ concentration and stop the decrease in $\mathrm{O}_{1}$ band intensity during annealing which was mentioned in Section 2.

\section{Conclusions}

The results presented above show that in Si crystals containing oxygen at the concentration higher than $10^{18}$ $\mathrm{cm}^{-3}$, irradiation by high energy electrons leads to the emergency of an additional channel for annihilation of I and $\mathrm{V}$ on oxygen atoms, because the concentration of VO complexes is high enough (more $2 \times 10^{17} \mathrm{~cm}^{-3}$ ). This results in the decrease of the introduction rate of A-centers and of the stationary concentration of the free intrinsic interstitials. The dominating defects were divacancies $\mathrm{V}_{2}$ and A-centers. The concentration of other radiation defects connected with donors or acceptors of different chemical nature were considerably lower. During irradiation the vacancies formed are captured by oxygen atoms (also by $\mathrm{O}^{*}$ centers) leading to the formation of A-centers. The subsequent heating to temperatures activating A-centre motion, a variety of sinks come to participate in A-centre capture.

In the temperature range of $300^{\circ} \mathrm{C}-350^{\circ} \mathrm{C}$ the diffusion activation of A-centers occur, which results in their capture by different types of centers. Some of them hold vacancy (vacancy trapping centers) which can participate in reactions between point defects at higher temperatures. In other centers, which capture A-centres the vacancy annihilates. The third type of capture canters holds the oxygen atom alone. A vacancy is set free following A-centre capture by $\mathrm{O}_{1}$ atoms on other defects. Part of the released vacancies captured on $\mathrm{O}_{1}$, transports isolated oxygen atoms in the form of A-centers to other centers, i.e. acts as a catalyst for the reaction of oxygen atom coagulation in silicon at temperatures at which in the absence of vacancies $\mathrm{O}_{1}$ atoms are immobile and do not react. The number of released vacancies decreases over time, owing to the capture by annihilation and recombination centers. Such a decrease in the number of free vacancies can be attributed to their capture by inter-phase 
boundaries, surfaces, dislocations, or other defects. The set of reactions with A-centre participation is determined by the assortment of defects in the original sample and can vary widely with production conditions, doping, and thermal treatment of the specimens.

\section{Acknowledgements}

This work was partly supported by the State Committee of Science MES Republic of Armenia in frame of the research project grant № 14AR-1c02.

\section{References}

[1] Muller, S.H., Sprenger, M., et al. (1978) Solid State Communications, 25, 987. http://dx.doi.org/10.1016/0038-1098(78)90889-X

[2] Trambetta, J.M., Watkins, G.D., et al. (1997) Journal of Applied Physics, 81, 1109. http://dx.doi.org/10.1063/1.363854

[3] Kaiser, W. (1957) Physical Review, 105, 1751. http://dx.doi.org/10.1103/PhysRev.105.1751

[4] Kaiser, W., Frisch, H.L. and Reiss, H. (1958) Physical Review, 112, 1546. http://dx.doi.org/10.1103/PhysRev.112.1546

[5] Mordkovich, V.N. (1964) Fizika Tverdogo Tela, 6, 847.

[6] Ramdas, A.K. and Rao, M.G. (1966) Physical Review, 142, 451. http://dx.doi.org/10.1103/PhysRev.142.451

[7] Corbett, J.W., Watkins, G.D. and McDonald, R.S. (1964) Physical Review, 135, A1381. http://dx.doi.org/10.1103/PhysRev.135.A1381

[8] Pajot, B. (1969) Solid State Electronics, 12, 923. http://dx.doi.org/10.1016/0038-1101(69)90051-3

[9] Watkins, G.D., Corbett, J.W. and Walker, R.M. (1959) Journal of Applied Physics, 30, 1198. http://dx.doi.org/10.1063/1.1735293

[10] Watkins, G.D. (1965) Radiation Damage in Semiconductors. Dunod, Paris, 97.

[11] Sokolov, S.N. and Silin, I.N. (1961) Preprint JINR (Dubna), D810.

[12] Arai, T. (1962) Journal of the Physical Society of Japan, 17, 246. http://dx.doi.org/10.1143/JPSJ.17.246

[13] Bean, A.R., Newman, R.C. and Smith, R.C. (1970) Journal of Physics and Chemistry of Solids, 31, 739. http://dx.doi.org/10.1016/0022-3697(70)90207-6

[14] Yeritsyan, H.N., Sahakyan, A.A., Grigoryan, N.E., et al. (2015) Journal of Modern Physics, 6, 1270. http://dx.doi.org/10.4236/jmp.2015.69132

[15] Emtsev, V.V., Ivanov, A.M., et al. (2012) Fizika i Technika Poluprovodnikov, 46, 473. 